PROFESIONALES Y HERRAMIENTAS PARA EL DESARROLLO LOCAL Y SUS SINERGIAS TERRITORIALES. EVALUACIÓN Y PROPUESTAS DE FUTURO IX Coloquio Nacional de Desarrollo Local del GTDL-AGE 

ANTONIO MARTÍNEZ PUCHE, XAVIER AMAT MONTESINOS, ISABEL SANCHO CARBONELL y DANIEL SANCHIZ CASTAÑO (EDS.)

\section{PROFESIONALES Y HERRAMIENTAS PARA EL DESARROLLO LOCAL Y SUS SINERGIAS TERRITORIALES. EVALUACIÓN Y PROPUESTAS DE FUTURO}

IX Coloquio Nacional de Desarrollo Local del GTDL-AGE

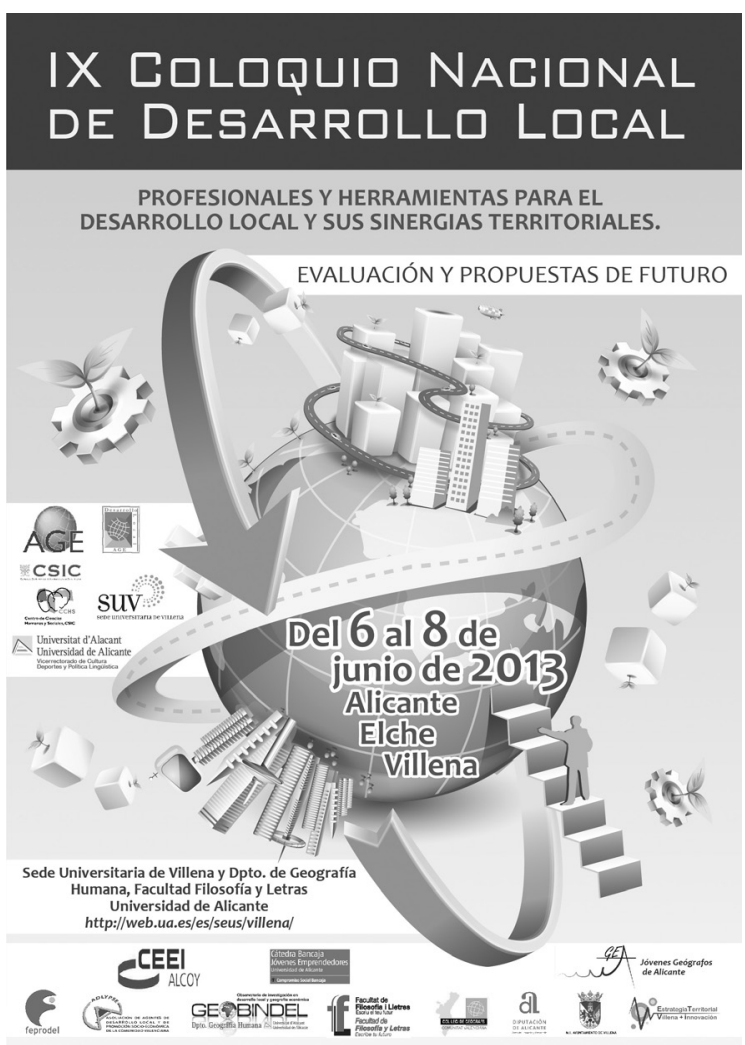


Este libro ha sido examinado y valorado por evaluadores ajenos a la Universidad de Alicante, con el fin de garantizar la calidad científica del mismo.

Publicacions de la Universitat d'Alacant

03690 Sant Vicent del Raspeig

Publicaciones@ua.es

http://publicaciones.ua.es

Telèfon: 965903480

(C) Antonio Martínez Puche, Xavier Amat Montesinos,

Isabel Sancho Carbonell y Daniel Sanchiz Castaño (eds.), 2016

(C) d'aquesta edició: Universitat d'Alacant

ISBN: 978-84-16724-00-0

Dipòsit legal: A 92-2016

Disseny de coberta: candela ink

Composició: Página Maestra (Miguel Ángel Sánchez Hernández)

Impressió i enquadernació: Guada Impresores

\section{unte \\ Unión de Editoriales
Universitarias Españolas \\ WWW.une.es
WWA}

Esta editorial es miembro de la UNE, cosa que garantiza la difusión y comercialización nacional y internacional de sus publicaciones.

Reservados todos los derechos. Cualquier forma de reproducción, distribución, comunicación pública o transformación de esta obra sólo puede ser realizada con la autorización de sus titulares, salvo excepción prevista por la ley. Diríjase a CEDRO (Centro Español de Derechos Repográficos, www.cedro.org) si necesita fotocopias o escanear algún fragmento de esta obra. 


\section{PRESENTACIÓN}

Ha tenido Villena el privilegio y honor de acoger una parte de la celebración de IX Coloquio Nacional de Desarrollo Local de la Asociación de Geógrafos Españoles-AGE. Con el título "Profesionales y herramientas para el desarrollo local y sus sinergias territoriales. Evaluación y propuestas de futuro" más de cien personas venidas de diferentes partes de España, profesionales, investigadores/as, técnicos de desarrollo local, responsables públicos, se dieron cita para profundizar en un abanico de alternativas que, cargadas de esperanza en la acción social y comunitaria, ofrecieran horizontes positivos en estos momentos de crisis.

Ha sido una auténtica alegría comprobar cómo la crisis especulativa, económica y ecológica que vivimos como sociedad y que a tanta gente ha dejado en la cuneta y tantos ecosistemas destrozados, se puede convertir en revulsivo para buscar nuevos caminos al desarrollo y a la participación. Una satisfacción saber no sólo que de la amenaza surge la oportunidad, sino que desde la experiencia técnica y profesional se generan herramientas válidas, firmes brújulas, que permiten orientar pasos para un desarrollo local con nuevos paradigmas que trata de superar estereotipos que no se pueden sostener ni económica ni medioambientalmente.

Una ciudad como Villena (Alicante), con sus casi 35.000 habitantes, que tuvo hace 30 años (los cumplirá este 2016), la primera agencia de desarrollo local de Alicante, y la $3^{\text {a }}$ de la Comunidad Valenciana, recibía a un nutrido grupo de personas que, herederas de aquella primera iniciativa, continúan apostando por proseguir rutas que mejoren la calidad de vida de la población desde un desarrollo sustentable e integrado. Nuestra localidad se vió agraciada por este encuentro y al tiempo reafirmada en sus opciones que, pioneras entonces (1986), se renuevan, transforman y amplían treinta años más tarde para cubrir un espectro mayor de retos, de necesidades y de iniciativas. Y no sólo porque estas personas pudieran conocer la ciudad y hacer algún gasto en la misma (lo cual siempre es de agradecer), sino sobre todo porque ofrecieron su experiencia y conocimiento al tiempo que captaron nuestra identidad y saber. 
Lugares emblemáticos de Villena como el salón de plenos del Ayuntamiento o el edificio de la Tercia (antiguas escuelas públicas y actual ubicación de la Sede Universitaria) sirvieron para el encuentro, la exposición y el debate. Pudimos conocer sobre nuestras propias experiencias de la mano de grandes profesores como D. Vicente M. Zapata que en su conferencia "Los procesos de innovación social mediante la participación ciudadana como estrategia para el desarrollo local" pone rostro y nombre propio al Foro Económico y Social de la localidad.

Pero más allá de nombres, la orientación del encuentro posibilitó un intercambio de experiencias en el que una ciudad como Villena quiere permanecer. Porque se trata de romper la venda que ciega algunos ojos que confunden desarrollo con cartera como lo hace el necio con valor y precio. Se trata de descubrir los valores de cada territorio y hacer de ellos una oportunidad para el desarrollo, de sentir la capacidad múltiple de adaptación, de encontrar en nuestros grupos sociales la capacidad de organización y regeneración. De saber del cúmulo de riqueza que hay en la manera de entender la vida y el trabajo, la tradición y la fiesta, la capacidad de acogida al visitante y el entretenimiento.

Nuestro término municipal, nuestra ciudad, es rica en patrimonio histórico, artístico, social, medioambiental, paisajístico, industrial... Y es rica también en personas con capacidad de emprender, en juventud, en iniciativas... Tiene una amalgama de valores que permite recibir con agrado las aportaciones plurales que ha propiciado este IX Coloquio Nacional de Desarrollo Local de la Asociación de Geógrafos Españoles. Y se convierte en caja de resonancia de una reflexión abierta y variada que cuestiona modelos conservadores de confundir riqueza únicamente con economía. La capacidad de un pueblo de crecer en identidad, de recrearse, de ofrecerse, de organizarse, de generar valor desde sus posibilidades y habilidades es un reto que conecta directamente con las nuevas líneas de trabajo en desarrollo local y que en estos días de encuentro pudimos extraordinariamente comprobar.

La crisis no ha venido dada, se ha forjado como proceso especulativo que poco tiene que ver con desarrollo. Pero como sacudida, nos ofrece la posibilidad de reformular conceptos y experiencias, articular pensamientos y consensos, ahondar en posibilidades novedosas, visualizar un horizonte que apenas sí se insinúa y convencerse de la necesidad de un nuevo modelo de desarrollo en el que más allá de IPC`s y rentas, se ubiquen cotas de bienestar social, de calidad de vida, de cohesión social, de convivencia, de respeto medioambiental, etc.

Acabamos de celebrar el X aniversario de la sede universitaria en Villena. Con él una cantidad ingente de actividades y experiencias que nos recuerdan que el desarrollo de una ciudad va unido también al arte, a la cultura, a la creación, a la innovación, al entretenimiento, al ocio, a la solidaridad. Con 


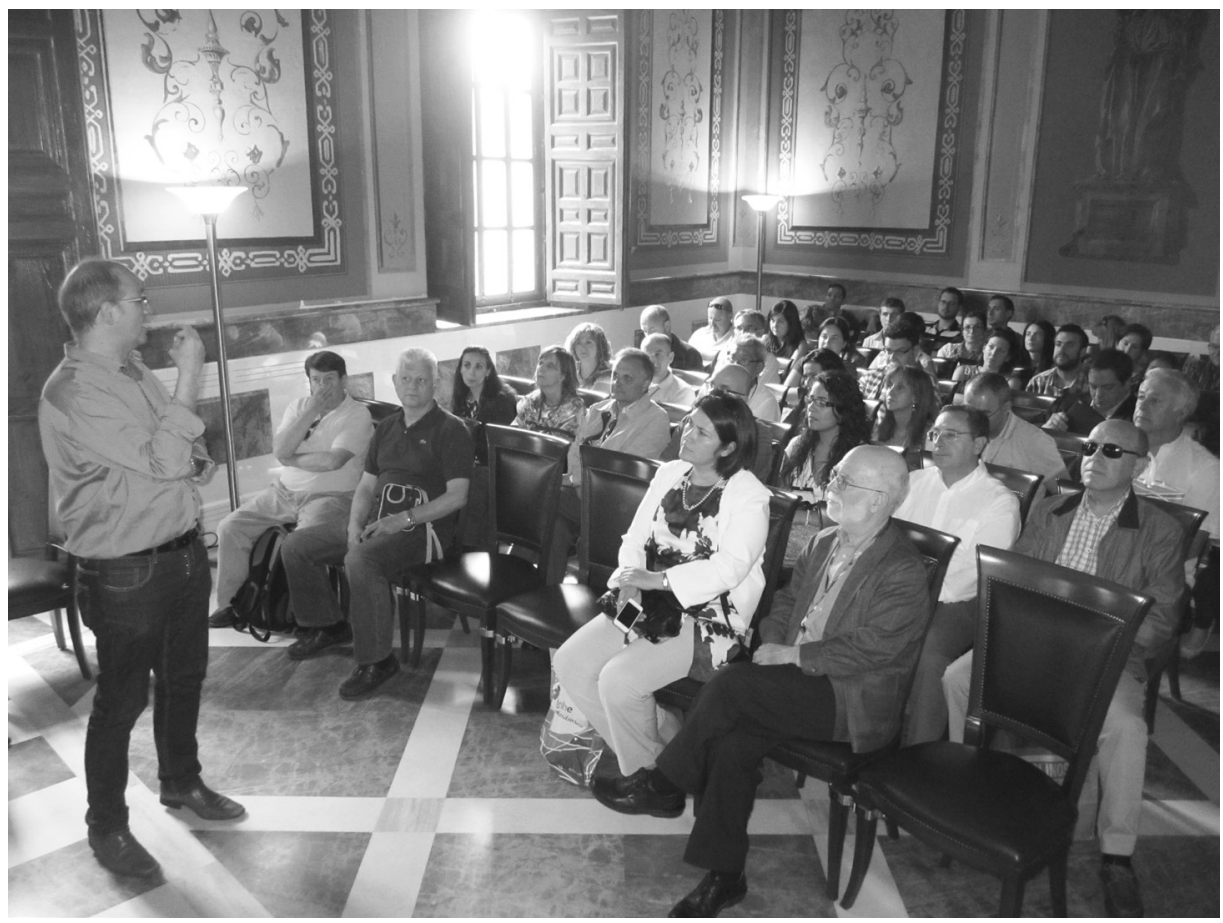

Imagen 1. Recepción Oficial en el Salón de Plenos del M.I. Ayuntamiento de Villena, a los congresistas por parte del Alcalde del Municipio, FJ. Esquembre. En primera fila, a la derecha, el profesor Vázquez Barquero, ponente inaugural del IX Coloquio Nacional.

la Universidad de Alicante hemos compartido aprendizaje y saber, y hemos descubierto nuevas capacidades que nos permiten creer en nuestra gente y sus potencialidades. Por ello hablar de desarrollo y mirar al futuro nos permite superar el vértigo de ese vacío que ha generado la visión economicista en esta materia, el cortoplacismo y la falta de orientación estratégica al respecto. Podemos creer en nuestra capacidad y captar las experiencias que unen territorio rural y urbano, agroecología e industria, iniciativa y planificación, biodiversidad y cultura.

La ruralidad, los recursos naturales, la cooperación, la organización comunitaria, el emprendedurismo nutren nuestra manera de ver la vida y nos ofrecen posibilidades para creer que otro desarrollo, como otro mundo, es posible, para que haya menos llanto, para que la exclusión social deje de ser una realidad cotidiana y el desarrollo local una quimera al alcance sólo de unas minorías que lo convierten en crecimiento insostenible y expoliador. 